\title{
'One I did earlier' ... \\ epidural steroid injections for low back pain with radicular symptoms
}

\author{
Chris Kelly, FRCA
}

In the first of an occasional series on medical procedures, Dr Chris Kelly, specialist registrar in Anaesthesia and Pain Medicine, takes a critical look at epidural steroids and examines the 'best practice' guidance from his professional body.

The use of anaesthetic agents via the epidural space was first described in 1901, but primarily for urological procedures. It was not until 1921 that a Spanish military surgeon, Fidel Pages, developed the modern technique of lumbar epidural. This was then popularised through the 1930s.(1) Epidural steroid injections were first used in the treatment of lumbar radicular pain syndromes by Robechi in 1952..2) It was only in 1960, in the United States, that the first study showing effectiveness in nerve root conditions was performed. ${ }^{(3)}$

Since then, there have been some 35 controlled studies of the effectiveness of epidural steroids for radicular back pain. It is presumed that the corticosteroids reduce the inflammatory response to irritation at the nerve root. Given that this is a common procedure for a very common condition, having a good evidence base would be highly desirable. Unfortunately it has been difficult to establish in this complex area of therapeutics.

The purpose of this article is to review the current injection techniques used in the treatment of radicular low back pain and the evidence for them. Practitioners have the choice of midline (interlaminar), transforaminal or caudal routes to the epidural space. We hope to clarify best practice when conducting these injections.

Since a landmark study, the use of steroid injections for radicular back pain has been standard practice and is accepted to have benefit in the short term (weeks to months). ${ }^{(4)}$ Since then there have been numerous citations in the literature to support this practice..$^{(5-10)}$ It is, however, not clear from the literature whether or not there is longterm benefit to these

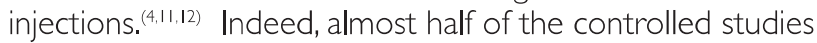
performed showed no benefit. These papers also highlight some of the difficulties alluded to earlier that may give rise to contradictory reports; it is all but impossible to standardise patient selection, methodology, treatments and outcomes. It has been noted in a recent British Medical Journal editorial that authors who perform these procedures are more likely to find benefit. ${ }^{(13)}$

In order to achieve the highest possible concentration of steroid to the nerve route for a given dose, it has been suggested that the transforaminal route would be a better approach than interlaminar. Some support of this claim has been given by a team looking to the evidence for superior short-term benefit over interlaminar approach. ${ }^{(12)}$ Perhaps the

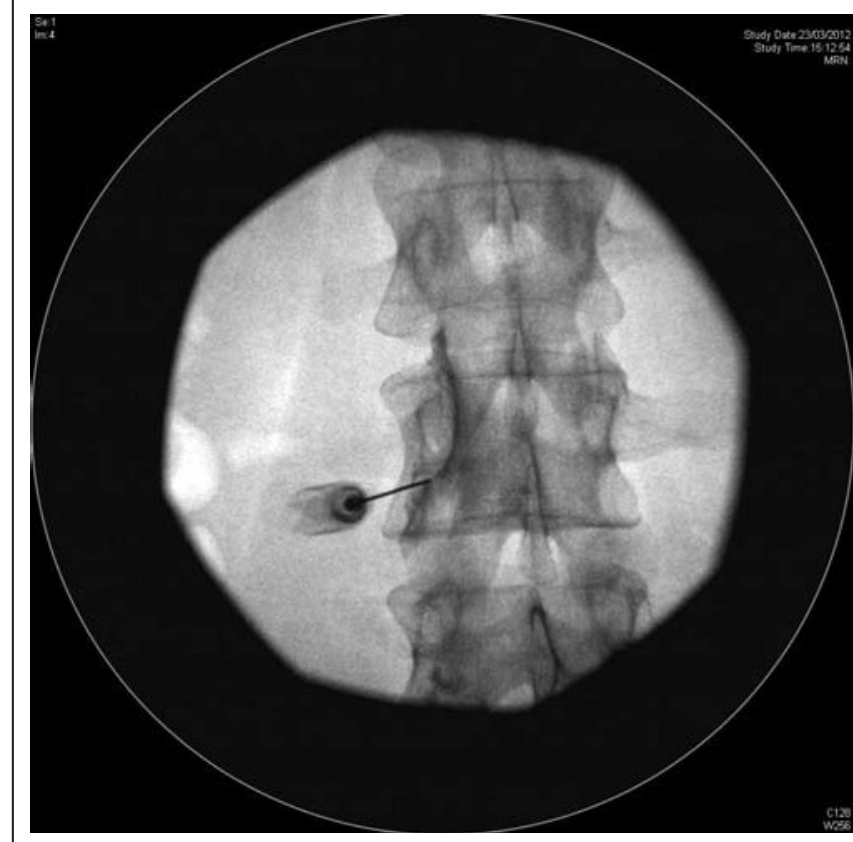

Figure I This demonstrates a transforaminal epidural through the left L4 foramen with contrast medium in the epidural space

most compelling evidence of a difference between the approaches comes from a randomised, blinded, prospective outcome study by Gharibo et al.(14) This group found that there were subjective reductions in pain scores when transforaminal injections were compared to interlaminar. It is worth noting, however, that the paper still recommended the interlaminar approach in order to avoid the potential complications of direct nerve damage or spinal artery puncture. There is also evidence to support the claim that a transforaminal approach may have superior effectiveness in the longterm, potentially reducing the requirement for surgery or repeat injections. ${ }^{(15,16)}$

This already complicated picture becomes more so when the evidence is examined for injections of steroid via the caudal route. This practice is becoming more common in some areas and works under the same basic assumptions that steroid delivered to the epidural space will reduce pain, even if it is delivered at a site distant from the presumptive lesion. The literature is, however, conflicted. A study comparing caudal injection of steroid in local anaesthetic (common practice) with caudal injection of sterile water demonstrated improvement in both groups. ${ }^{(17)}$ The improvement was faster and more complete in the group receiving steroids. At odds with this result is a recent paper in the British Medical Journal where patients were randomised to caudal epidural, caudal saline sham procedures. ${ }^{(18)}$ The authors found no statistically significant difference between the groups. Although it was 
noted that the study could have been underpowered, it is difficult to explain the difference in result. There is certainly less in the literature to support the use of caudal injections for radicular low back pain.

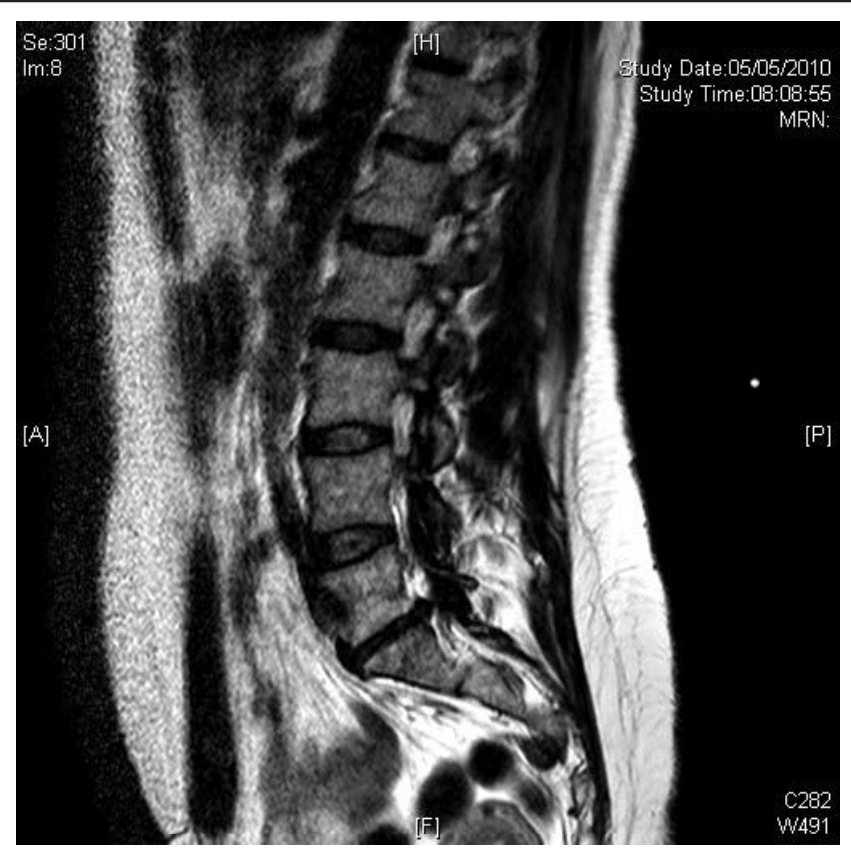

Figure 2 MR scan showing an L5/SI disc prolapse. Putting the needle above the level of root compression allows easy access to the space close to the level of the lesion. A dose of $4 \mathrm{ml}$ of local anaesthetic and $40 \mathrm{mg}$ of Kenalog is used, lower than that used by the caudal route

It is standard practice to use fluoroscopic guidance when performing interlaminar and transforaminal approaches. This is because it provides a firm end point for the procedure and confidence is required if subsequent clinical decisions are going to be based on effects of the injection. It has also been well established that real-time imaging will reduce the incidence of complications and failed procedure. ${ }^{(19,20)}$ Two studies of caudal injection of steroids did not make use of fluoroscopy when all other papers cited have. This is in spite of there being evidence in the literature that fluoroscopy can improve the accuracy of needle placement. ${ }^{(21)}$

\section{Royal College of Anaesthetists/ British Pain Society Guidelines ${ }^{(22)}$}

Epidural injection for patients with pain of spinal origin should be performed under fluoroscopic guidance. Studies indicate that in a significant number of patients the needle may not be correctly sited if epidural injection is performed without fluoroscopy. Further decisions about management are often determined by the outcome of an epidural injection, so it is important to confirm the accurate placement of the epidural needle and the spread of the injectate.
It is also worth noting guidance from the Royal College of Anaesthetists Faculty of Pain Medicine. This was produced in April $201 \mathrm{I}$ and speaks directly to the conditions under which the procedures should take place. It stresses the importance of a clean environment and asepsis in an area large enough to accommodate all the equipment required. Because there is a risk of intravenous or intrathecal injection of local anaesthetic with subsequent cardiovascular collapse, IV access should be obtained, full resuscitation equipment should be available and trained assistance to hand. Specifically with steroid injections, it is suggested that fluoroscopic guidance is mandatory due to the difficulty of establishing a suitable end point without it. ${ }^{(22)}$

This is a complex area with an often contradictory evidence base. From the most recent reviews of the literature it seems that there is support of steroid injections. This is within a carefully selected group of patients with radicular symptoms in the sub-acute setting. However, their use needs to be carefully regulated by clinicians, particularly as they are used in the epidural space outside of their product licence.

Do you perform a medical procedure which you consider few people understand or know about? Would you like to communicate with your colleagues in the Morecambe Bay area about recent advances in techniques in your specialty? Please write to the Editor, including your contact details, and we will include an article, together with details of access to the service, in future issues under the by-line 'One I did earlier'. . .

The Pain Service can be contacted via the Community Patient Contact Centre, Westmorland General Hospital. The service is based at Westmorland General Hospital and its 12 clinics a week are held at all the main Trust locations around the Bay.

\section{REFERENCES}

I. Diz JC, Franco A, Bacon DR, Rupreht J, Alvarez J, eds. The history of anesthesia: proceedings of the Fifth International Symposium. Elsevier; 2002. Pp205-6

2. Robechhi A, Capra R. Lidrocortisone (Composto F), rime esperinxe cliniche in campo reumatolgico. Minerva Med 1952;98:1259-63

3. Benson $H$. Epidural steroid injections for low back pain and lumbosacral radiculopathy. Pain 1986;24:277-95

4. Carette S, Leclaire R, Marcoux S, et al. Epidural corticosteroid injections for sciatica due to herniated nucleus pulposus. N Engl J Med 1997;336: I634-40 
5. Chou R, Huffman L. Guideline for the Evaluation and Management of Low Back Pain: Evidence Review. Glenview, IL: American Pain Society; 2009

6. Manchikanti L, Boswell MV, Singh V, et al. Comprehensive evidence-based guidelines for interventional techniques in the management of chronic spinal pain. Pain Physician 2009; 12:699-802

7. Manchikanti L, Datta S, Derby R, Wolfer LR, Benyamin RM, Hirsch JA. A critical review of the American Pain Society clinical practice guidelines for interventional techniques: Part I. Diagnostic interventions. Pain Physician 2010; 13:EI4I-74

8. Manchikanti L, Datta S, Gupta S, et al. A critical review of the American Pain Society clinical practice guidelines for interventional techniques: Part 2. Therapeutic interventions. Pain Physician 2010; 1 3:E215-64

9. Bogduk N, Christophidis N, Cherry D, et al. Epidural use of steroids in the management of back pain. Report of working party on epidural use of steroids in the management of back pain. Canberra, Commonwealth of Australia: National Health and Medical Research Council; 1994. Pp |-76

10. Staal JB, de Bie R, de Vet HC, Hildebrandt J, Nelemans P. Injection therapy for subacute and chronic low-back pain. Cochrane Database Syst Rev 2008;3:CD00 824

I I. Parr AT, Diwan S, Abdi S. Lumbar interlaminar epidural injections in managing chronic low back and lower extremity pain: A systematic review. Pain Physician $2009 ; \mid 2: 163-88$

12. Buenaventura RM, Datta S, Abdi S, Smith HS. Systematic review of therapeutic lumbar transforaminal epidural steroid injections. Pain Physician 2009; |2:233-5 |

13. Cohen SP. Epidural steroid injections for low back pain. Br Med J 201 1;343:d5310

14. Gharibo CG,Varlotta GP, Rhame EE, Liu EC, Bendo JA, Perloff MD. Interlaminar versus transforaminal epidural steroids for the treatment of subacute lumbar radicular pain: a randomized, blinded, prospective outcome study, Pain Physician 201 I; | 4(6):499-5 I I
15. VadVB, Bhat AL, Lutz GE, Cammisa F.Transforaminal epidural steroid injections in lumbosacral radiculopathy: A prospective randomized study. Spine (Phila Pa 1976) 2002;27:1 1-16.

16. Riew KD, Yin Y, Gilula L, et al. The effect of nerve-root injections on the need for operative treatment of lumbar radicular pain. A prospective, randomized, controlled, double-blind study. J Bone Joint Surg Am 2000;82-A: I 589-93

17. Sayegh FE, Kenanidis El, Papavasiliou KA, Potoupnis ME, Kirkos JM, Kapetanos GA. Efficacy of steroid and nonsteroid caudal epidural injections for low back pain and sciatica: a prospective, randomized, double-blind clinical trial. Spine (Phila Pa 1976) 2009;34(I4): I 44I-7

18. Iversen T, Solberg TK, Romner B, et al. Effect of caudal epidural steroid or saline injection in chronic lumbar radiculopathy: multicentre, blinded, randomised controlled trial. Br Med J 201 I;343:d5278

19. Cohen SP, Maine DN, Shockey SM, Kudchadkar S, Griffith S. Inadvertent disk injection during transforaminal epidural steroid injection: steps for prevention and management. Pain Medicine 2008;9(6):688-94

20. Bartynski WS, Grahovac SZ, Rothfus WE. Incorrect needle position during lumbar epidural steroid administration: inaccuracy of loss of air pressure resistance and requirement of fluoroscopy and epidurography during needle insertion. Am J of Neuroradiol 2005;26(3):502-5

21. Ergin A, Yanarates O, Sizlan A, Orhan ME, Kurt E, Guzeldemir ME. Accuracy of caudal epidural injection: the importance of real-time imaging. Pain Pract 2005;5(3):25 I-4

22. Recommendations for good practice in the use of epidural injection for the management of pain of spinal origin in adults. London: Royal College of Anaesthetists; 2011. Available at: www/rcoa.ac.uk/fpm 